Article

\title{
Core-Shell Structure Design of Hollow Mesoporous Silica Nanospheres Based on Thermo-Sensitive PNIPAM and pH-Responsive Catechol-Fe ${ }^{3+}$ Complex
}

\author{
Weili Peng, Zeping Zhang *(D), Minzhi Rong * and Mingqiu Zhang \\ Key Laboratory for Polymeric Composite and Functional Materials of Ministry of Education, GD HPPC Lab, \\ School of Chemistry, Sun Yat-sen University, Guangzhou 510275, China; pengweil@mail2.sysu.edu.cn (W.P.); \\ ceszmq@mail.sysu.edu.cn (M.Z.) \\ * Correspondence: zhangzp8@mail.sysu.edu.cn (Z.Z.); cesrmz@mail.sysu.edu.cn (M.R.)
}

Received: 15 October 2019; Accepted: 5 November 2019; Published: 7 November 2019

\begin{abstract}
A kind of core-shell hybrid nanoparticle comprised of a hollow mesoporous silica nanoparticles (HMS) core and a copolymer shell bearing $\mathrm{N}$-(3,4-dihydroxyphenethyl) methacrylamide (DMA) and $\mathrm{N}$-isopropylacrylamide (NIPAM) as responsive moieties was prepared. Moreover, the factors that could impact the surface morphology and hierarchical porous structure were discussed. In the presence of $\mathrm{Fe}^{3+}$, catechol- $\mathrm{Fe}^{3+}$ complexes were formed to achieve $\mathrm{pH}$-responsive polymer shell, combining with thermal-sensitiveness of poly(N-isopropylacrylamide). Doxorubicin (DOX) was applied as a model drug and the behaviors of its loading/release behaviors were investigated to prove the idea. The results exhibited a significant drug loading capacity of $8.6 \%$ and embed efficiency of $94.6 \%$ under $1 \mathrm{mg} \mathrm{ml}^{-1}$ DOX/PBS solution. In fact, the loading capacity of drug can be easily improved to as high as $28.0 \%$ by increasing the DOX concentration. The vitro cytotoxicity assay also indicated that the as-prepared nanoparticles have no significant cytotoxicity on RAW 264.7 cells. The in vitro experiment showed that the cumulative release of DOX was obviously dependent on the temperature and $\mathrm{pH}$ values. This $\mathrm{pH} /$ temperature-sensitive hollow mesoporous silica nanosphere is expected to have potential applications in controlled drug release.
\end{abstract}

Keywords: hollow mesoporous silica microspheres; thermo-responsive; $\mathrm{pH}-$ responsive; catechol-Fe $^{3+}$; controlled release

\section{Introduction}

The construction of smart delivery systems for drugs, such as polymeric hydrogels [1], micelles [2], liposomes [3], various inorganic [4], and organic-inorganic hybrid nanoparticles [5], has been attracting great attentions in recent years. Among them, hollow mesoporous silica (HMS) nanoparticles have the advantages of good biocompatibility, large hollow space, highly ordered mesopores, high surface areas, and easily functionalized surface, showing potential applications as an ideal carrier for delivery systems. [6,7] However, unmodified HMS lacks of controlled drug release ability, satisfactory dispersity, and stability, which highlights the importance of surface modification. [8] Numerous studies have shown that drug release from these sophisticatedly engineered multifunctional nanocontainers with appropriate surface modification could be commonly controlled by the triggering of time [9], pH [10,11], redox [12], temperature [13], and magnetic field [14]. It is widely known that tumor tissues have both lower $\mathrm{pH}$ value $[15,16]$ and higher temperature [17] as compared to normal tissues. Consequently, $\mathrm{pH}-$ and temperature-responsive polymer-modified HMS that could open the pores in either lower $\mathrm{pH}$ or higher temperature should promote the drug release in specific tumor sites. Furthermore, previous researches have also indicated that the appropriate physical characteristic (e.g., stiffness, size and shape) of nanoparticles was beneficial for efficient drug delivery. [18,19] 
Poly(N-isopropylacrylamide) (PNIPAM), as one of the most widely investigated temperature-responsive polymers, exhibits a phase transition abruptly at a lower critical solution temperature (LCST) of about $32{ }^{\circ} \mathrm{C}$. Below the LCST, the polymer is in the coil (soluble) state with strong hydrogen bonding between the amide groups of PNIPAM and surrounding water molecules. Above the LCST, PNIPAM turns into a collapsed (insoluble) state due to the increase of hydrophobic association. This character has been widely utilized for thermo-responsive drug delivery [20,21].

Marine mussels are a fascinating species that can anchor themselves to the turbulent intertidal zone by secreting byssal adhesion protein to form an adhesive plaque. This class of proteins contains lots of 3,4-dihydroxyphenylalanine (DOPA) residues, which can form robust complexes with iron (III) ions $\left(\mathrm{Fe}^{3+}\right)$. The catechol- $\mathrm{Fe}^{3+}$ coordination numbers have been widely proven to be adjustable in the order of mono-, bis-, and tris-catechol complex when the $\mathrm{pH}$ is increased from about 4 to 9. [22,23] Therefore, $\mathrm{pH}$-responsive biomimetic drug delivery hydrogel can be designed on the basis of the above properties of catechol-Fe ${ }^{3+}$ coordination system. $[1,24,25]$ However, there are few applications of this coordination chemistry in HMS surface modification and controlled drug release so far.

Herein, HMS with abundant mesoporous structure were firstly prepared by template method (Figure 1a). Subsequently, the vinyl groups were incorporated into the surface of HMS by reacting with silane coupling agent KH570, followed by surface seed precipitation copolymerization to achieve linear poly(N-isopropylacrylamide-co-N-(3,4-dihydroxyphenethyl) methacrylamide) copolymer-grafted HMS (HMS@P(NIPAM-co-DMA)) (Figure 1b). Afterwards, the polymer shell was functionalized in the presence of $\mathrm{Fe}^{3+}$ to form the catechol- $\mathrm{Fe}^{3+}$ complex, leading to a $\mathrm{pH} /$ temperature-sensitive nanoparticle (HMS@P(NIPAM-co-DMA-Fe ${ }^{3+}$ )). The morphology, structure, and structure-property relationship of unmodified and modified HMS are studied and characterized in detail. In addition, doxorubicin (DOX) was used as a model drug to prove the drug loading ability and $\mathrm{pH} /$ temperature responsive release behavior of the modified HMS.

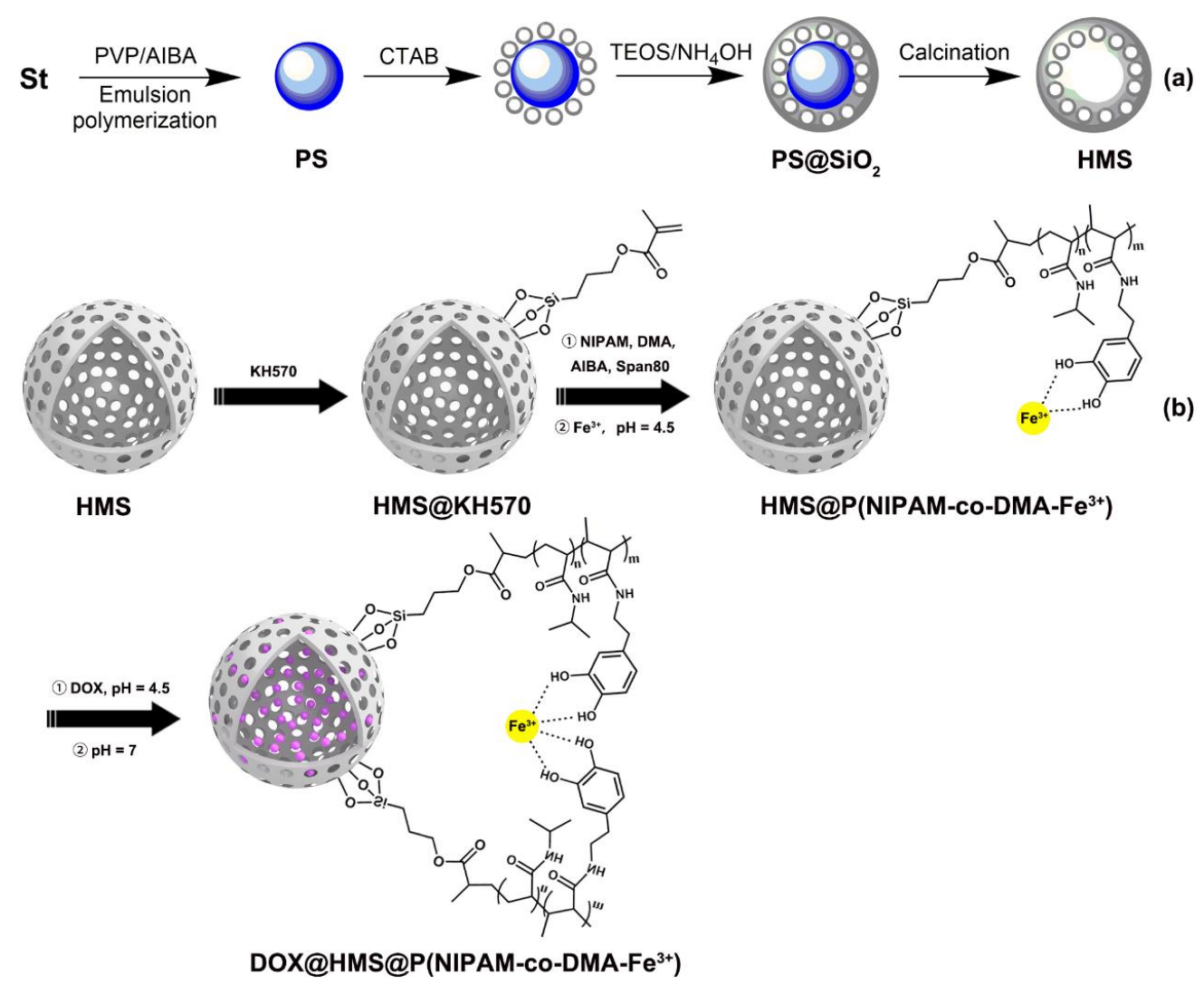

Figure 1. Cont. 


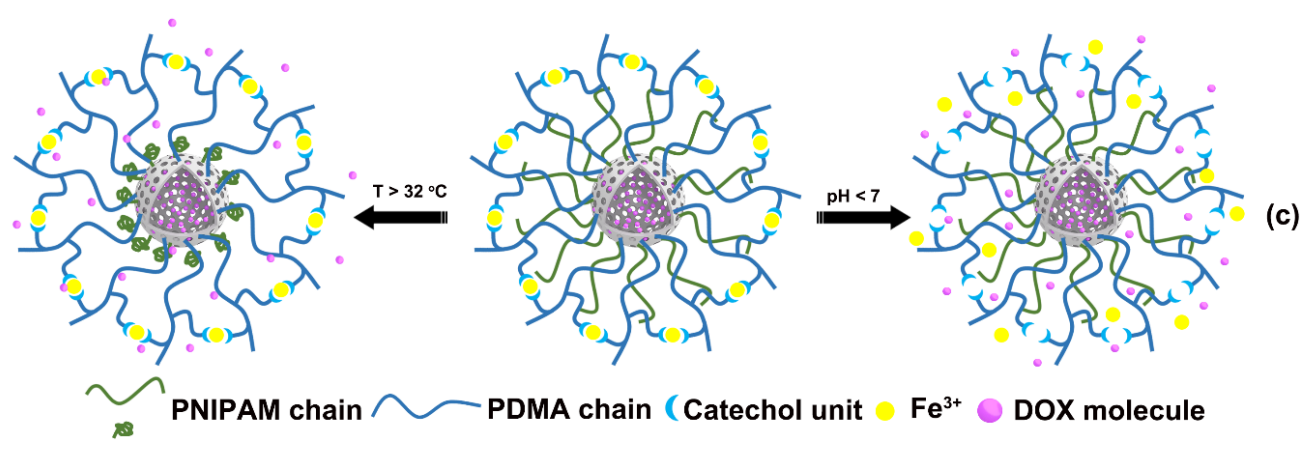

Figure 1. Schematic illustration of the synthesis process of (a) hollow mesoporous silica (HMS) and (b) doxorubicin (DOX)@HMS@P(NIPAM-co-DMA-Fe ${ }^{3+}$ ). (c) Schematic diagram of drug release.

\section{Materials and Methods}

\subsection{Materials}

Styrene (St), tetraethoxysilane (TEOS), ammonia, sodium tetraborate, sodium bicarbonate, sodium hydroxide, anhydrous magnesium sulfate $\left(\mathrm{MgSO}_{4}\right)$, Span80, potassium dihydrogen phosphate, sodium hydrogen phosphate, sodium chloride, and potassium chloride were purchased from Guangzhou Chemical Reagent Factory, Guangzhou, China. 2,2'-Azobis(2-methylpropionamidine) dihydrochloride (AIBA, 97\%), hexadecyl trimethyl ammonium bromide (CTAB, 99\%), polyvinylpyrrolidone (PVP, k29-32), dopamine (98\%), methacrylic anhydride (94\%), N-isopropylacrylamide (NIPAM, 98\%), and 3-methacryloxyporpyltrimethoxysilane (KH570, 97\%) were supplied by Shanghai Aladdin Biochemical Technology Co., Ltd., Shanghai, China. Doxorubicin (DOX) was obtained from Dalian Meilun Biotech Co., Ltd., Dalian, China. Styrene was purified by washing with alkaline and water, drying with anhydrous $\mathrm{MgSO}_{4}$, and vacuum distillation before use. All of the other chemicals and solvents were used as received.

\subsection{Synthesis of Polystyrene (PS) Sphere Template}

The monodisperse PS microspheres were synthesized by soap-free emulsion polymerization [26], as follows: $10.0 \mathrm{~g} \mathrm{St}, 90.0 \mathrm{~g} \mathrm{H}_{2} \mathrm{O}$, and a certain amount of PVP (i.e., $6 \mathrm{~g}, 4.5 \mathrm{~g}$, or $3 \mathrm{~g}$ ) were added into a $250 \mathrm{~mL}$ three-necked flask that was equipped with a mechanical stirrer. Subsequently, the mixture was synchronously stirred and bubbled with argon for $30 \mathrm{~min}$., followed by slowly heating to $60^{\circ} \mathrm{C}$. Subsequently, $10 \mathrm{ml}$ aqueous solution of AIBA $(0.26 \mathrm{~g})$ was dropped into the above mixture with a constant pressure dropping funnel. Finally, the reaction was refluxed at $70{ }^{\circ} \mathrm{C}$ for $24 \mathrm{~h}$ under argon atmosphere. After completion of the polymerization, the resultant PS emulsions (solid content $=10$ wt.\%) with a different average diameter and the yield of about $80 \%$ were collected.

\subsection{Synthesis of Hollow Mesoporous Silica Microspheres (HMS)}

Silica-coated PS core-shell microsphere (PS@SiO ${ }_{2}$ ) and hollow mesoporous silica microspheres (HMS) were fabricated by referring to literatures [27,28] (Figure 1a). PS emulsion (10 g, $10 \mathrm{wt} . \%)$, CTAB $(0.5 \mathrm{~g})$, absolute ethanol $(25 \mathrm{ml})$, and $10 \mathrm{~mL}$ of water were added into a $100 \mathrm{ml}$ three-necked flask and ultrasonic dispersed for $15 \mathrm{~min}$. Afterwards, the mixture was kept at $70^{\circ} \mathrm{C}$ and stirred, followed by the addition of $5 \mathrm{ml}$ TEOS/ethanol $\left(0.2 \mathrm{~g} \mathrm{ml}^{-1}\right)$ solution within $30 \mathrm{~min}$. (the mass ratio of TEOS to PS is 1). After reaction for $10 \mathrm{~min} ., 3 \mathrm{ml}$ of ammonia solution $\left(0.1 \mathrm{~mol} \mathrm{~L}^{-1}\right)$ was quickly added and stirred

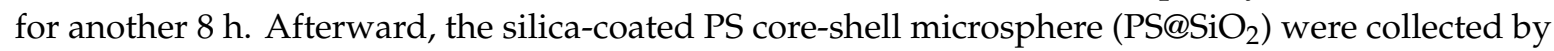
repeatedly centrifugation and washing with $50 \mathrm{wt} . \%$ ethanol several times, followed by vacuum drying at $60{ }^{\circ} \mathrm{C}$ overnight. Hollow mesoporous silica microspheres (HMS) were obtained after calcination in air at $300{ }^{\circ} \mathrm{C}$ for $2 \mathrm{~h}$ and then at $550^{\circ} \mathrm{C}$ for $5 \mathrm{~h}$. Fourier transform infrared (FTIR, Thermo Nicolet Corporation, Madison, WI, USA, KBr, Figure S1): $v=3340,1630,1090,960,800 \mathrm{~cm}^{-1}$. 


\subsection{Synthesis of N-(3,4-dihydroxyphenethyl) Methacrylamide (DMA)}

Typically, DMA was synthesized, as follows, by referring to the modified method [29] (Scheme S1). Sodium tetraborate $(2.0 \mathrm{~g})$, sodium bicarbonate $(0.8 \mathrm{~g})$, and $50 \mathrm{ml}$ of distilled water were added to a $100 \mathrm{ml}$ three-necked flask and stirred for $30 \mathrm{~min}$. in a nitrogen atmosphere to remove oxygen. Subsequently, dopamine hydrochloride (1.0 g) and tetrahydrofuran (THF) solution of methacrylic anhydride $(5 \mathrm{~mL}, 10 \mathrm{wt} . \%)$ were rapidly added to the reaction mixture, respectively. Afterwards, $\mathrm{NaOH}$ solution $\left(1 \mathrm{~mol} \mathrm{~L}^{-1}\right)$ was applied to adjust the $\mathrm{pH}$ to $>8$ and kept reacting for $16 \mathrm{~h}$. After reaction, the reaction mixture was extracted with ethyl acetate. The $\mathrm{pH}$ value of the collected water phase was adjusted to $<2$ and further extracted with ethyl acetate for several times. The organic phase was washed with distilled water, followed by drying overnight with anhydrous $\mathrm{MgSO}_{4}$, filtering, and concentrating. A certain amount of $n$-hexane was added to the concentrate solution and kept stirring for $8 \mathrm{~h}$ at $0{ }^{\circ} \mathrm{C}$. Whereafter, sage green powder with the yield of $55 \%$ was obtained by cold filtration and vacuum drying at $50{ }^{\circ} \mathrm{C}$ for $24 \mathrm{~h}$. FTIR (KBr, Thermo Nicolet Corporation, Madison, WI, USA, Figure S3): $v=3370,3200,3030,2930,2860,1650,1591,1556,1527,1449 \mathrm{~cm}^{-1}$; Proton nuclear magnetic resonance $\left({ }^{1} \mathrm{H}\right.$ NMR, Bruker, Karlsruhe, Germany, $400 \mathrm{MHz}$, DMSO-d6, $\delta$, Figure S4): 8.67 and 8.79 (s, $2 \mathrm{H} ; \mathrm{OH}), 7.97(\mathrm{t}, \mathrm{J}=5.2 \mathrm{~Hz}, \mathrm{H} ; \mathrm{NH}), 6.58 \sim 6.44(\mathrm{~m}, 3 \mathrm{H} ; \mathrm{Ar}-\mathrm{H}), 5.31$ and $5.63\left(\mathrm{~s}, 2 \mathrm{H} ;=\mathrm{CH}_{2}\right), 3.24(\mathrm{q}, \mathrm{J}=$ $\left.6.0 \mathrm{~Hz}, 2 \mathrm{H} ; \mathrm{CH}_{2}\right), 2.56\left(\mathrm{t}, \mathrm{J}=7.6 \mathrm{~Hz}, 2 \mathrm{H} ; \mathrm{CH}_{2}\right), 1.85\left(\mathrm{~s}, 3 \mathrm{H} ; \mathrm{CH}_{3}\right)$; Carbon 13 nuclear magnetic resonance $\left({ }^{13}\right.$ C NMR, Bruker, Karlsruhe, Germany, 400 MHz, DMSO-d6, $\delta$, Figure S5): 167.7, 145.5, 130.7, 119.6, $118.2,116.4,115.9,41.4,35.1,19.1$.

\subsection{Preparation of the KH570-Modified Silica Particle}

Piranha solution was firstly used to activate the hydroxyl groups since most of the hydroxyl groups on the HMS surface were inactivated after calcination [30]. The typical process was as follows: HMS was added to the mixture solution of concentrated sulfuric acid and hydrogen peroxide (volume ratio $=3: 1$ ), followed by ultrasonic dispersion and then refluxing at $100^{\circ} \mathrm{C}$ for $2 \mathrm{~h}$. Afterwards, the cool reaction mixture was centrifuged and then washed with ethanol and deionized water several times.

KH570 $(0.2 \mathrm{~mL})$ was firstly added to a toluene suspension $(30.0 \mathrm{~mL})$ of HMS $(0.1 \mathrm{~g})$. The reaction mixture was refluxed at $110{ }^{\circ} \mathrm{C}$ for $6 \mathrm{~h}$ under a nitrogen atmosphere. KH570-modified HMS was further purified by Soxhlet extraction with ethanol at $95^{\circ} \mathrm{C}$ for $24 \mathrm{~h}$ after four cycles of centrifugation (12000 rpm) and ultrasonic washing with ethanol and water. Finally, HMS@KH570 was obtained after vacuum drying at $50{ }^{\circ} \mathrm{C}$ for $12 \mathrm{~h}$ (grafting yields $\left.=14.8 \%\right)$. FTIR $(\mathrm{KBr}$, Thermo Nicolet Corporation, Madison, USA, Figure S6): $v=3370,3200,3030,2930,2860,1650,1591,1556,1527,1449 \mathrm{~cm}^{-1}$.

\subsection{Synthesis of HMS Nanoparticles Coated with Sensitive Polymer Shell}

Monodisperse HMS@P(NIPAM-co-DMA-Fe ${ }^{3+}$ ) cross-linked nanoparticles were synthesized, as follows. Briefly, HMS@KH570 nanoparticles $(0.1 \mathrm{~g})$, NIPAM $(0.8 \mathrm{~g})$, DMA $(0.2 \mathrm{~g})$, and $50 \mathrm{~mL}$ alcohol/water (volume ratio $=1: 4$ ) solution were added into a $100 \mathrm{~mL}$ three-necked flask equipped with a reflux condensing tube. Subsequently, the reaction mixture was heated to $70{ }^{\circ} \mathrm{C}$ and bubbled with nitrogen for $0.5 \mathrm{~h}$, followed by reacting for another $10 \mathrm{~h}$ in the presence of AIBA $(0.04 \mathrm{~g})$ as initiator. Afterwards, the resultant HMS@P(NIPAM-co-DMA) core-shell nanoparticles (grafting yields $=14.6 \%$ ) were purified by centrifugation and then washed with absolute ethanol.

Moreover, the unpurified mixture of HMS@P(NIPAM-co-DMA) was added into the $50 \mathrm{~mL}$ of $\mathrm{FeCl}_{3}$ containing PBS solution $\left(\mathrm{n}\left(\mathrm{Fe}^{3+}\right): \mathrm{n}(\mathrm{DMA})=1: 2, \mathrm{pH}=4.5\right)$ for catechol- $\mathrm{Fe}^{3+}$ mono or bis-coordination in order to form catechol- $\mathrm{Fe}^{3+}$ coordination bonds. The mixture was stirred for 48 $\mathrm{h}$ at room temperature, followed by centrifugation and vacuum drying at $50^{\circ} \mathrm{C}$ for $12 \mathrm{~h}$ to achieve HMS@P(NIPAM-co-DMA-Fe ${ }^{3+}$ ). 


\subsection{Characterization}

UV-vis spectra were obtained while using a Perkin-Elmer Lambda 750 UV/vis spectrophotometer. Fourier transform infrared (FTIR, Thermo Nicolet Corporation, Madison, WI USA) analysis was conducted on a Nicolet Avatar 330 FT-IR spectroscopy. ${ }^{1} \mathrm{H}$ NMR and ${ }^{13} \mathrm{C}$ NMR spectra were measured by an AVANCE III $400 \mathrm{MHz}$ (400 MHz, Bruker, Karlsruhe, Germany) with DMSO-d6 as solvent. X-ray photoelectron spectroscopy (XPS, Thermo Fisher Scientific, Waltham, USA) spectra were measured on a Thermo SCIENTIFIC ESCALAB 250Xi. The products were visualized while using a JEM-2010HR transmission electron microscope (TEM, Japan Electronics Co., Ltd, Tokyo, Japan) and Hitachi S4800 scanning electron microscopy (SEM, Hitachi, Tokyo, Japan). Dynamic light scattering (DLS, Brookhaven, NY, USA) was conducted on a BI-200SM. The nitrogen adsorption/desorption isotherms and pore-structure analysis were conducted by an ASAP2020 surface area analyzer (Micromeritics Instrument Corporation, AT, USA) at $77 \mathrm{~K}$. X-ray diffraction (XRD, Rigaku Corporation, Tokyo, Japan) patterns were obtained on a RIGAKU D-MAX 2200 VPC with $\mathrm{Cu}-\mathrm{K} \alpha(\lambda=1.54 \AA)$ radiation. The particle zeta potentials were measured with a ZetaPALS zeta potential analyzer (Brookhaven, New York, USA).

Temperature gravimetric Analysis (TGA, NETZSCH, Hanau, Germany) was conducted on a Netzsch TG-209 in $\mathrm{N}_{2}$ atmosphere. Grafting yields of KH570 and copolymer P(NIPAM-co-DMA) were calculated according to the following equations [31,32]:

$$
\mathrm{GY}=\left[\left(m_{a}-m_{b}\right) / m_{r}\right] \times 100 \%
$$

where $m_{b}$ and $m_{a}$ are the weight loss of nanoparticles between $250 \sim 800^{\circ} \mathrm{C}$ before and after modification, respectively; $m_{r}$ is the residue weight of nanoparticles.

The cytotoxicity of HMS@P(NIPAM-co-DMA-Fe ${ }^{3+}$ ) was carried out on RAW 264.7 cells by MTT assay. Typically, RAW 264.7 cells that were cultured in RPMI 1640 medium with $10 \%$ FBS and 1\% penicillin-streptomycin were seeded in 96-well plates at a density of 5000 cells/well. After incubating for $24 \mathrm{~h}$ in $\mathrm{CO}_{2}(5 \%)$ at $37^{\circ} \mathrm{C}$, fresh medium containing various amounts of HMS@P(NIPAM-co-DMA-Fe ${ }^{3+}$ ) was added. When the incubating time is 24 or $48 \mathrm{~h}$, the cells were washed with PBS and then incubated with fresh medium containing MTT $\left(0.5 \mathrm{mg} \mathrm{ml}^{-1}\right)$ for $4 \mathrm{~h}$. Afterwards, $200 \mu \mathrm{l}$ of dimethyl sulfoxide (DMSO) was added to each well and the optical density was measured at $550 \mathrm{~nm}$ with a Multiskan FC microplate reader (Thermo Fisher Scientific, Waltham, WI, USA). The cell viability was calculated, as follows: cell viability $=\left(\mathrm{OD}_{\text {sample }} / \mathrm{OD}_{\text {control }}\right) \times 100 \%$, where the sample represents the cells that were treated with HMS@P(NIPAM-co-DMA-Fe ${ }^{3+}$ ) and the control means non-treated cells.

\subsection{DOX Loading Capacity and Controlled Release Behaviors In Vito}

HMS@P(NIPAM-co-DMA-Fe $\left.{ }^{3+}\right)(50 \mathrm{mg})$ and $0.5 \mathrm{ml}$ DOX/DMSO solution $\left(10 \mathrm{mg} \mathrm{ml}^{-1}\right)$ was added to $4.5 \mathrm{~mL}$ of PBS solution $(\mathrm{pH}=4.5)$ and kept stirred at room temperature for $48 \mathrm{~h}$. At a $\mathrm{pH}$ value of 4.5, the catechol- $\mathrm{Fe}^{3+}$ coordination number is 1 , and thus the crosslinking density of copolymer is relatively lower, which is beneficial for the diffusion of DOX molecules into the nanoparticles. Subsequently, the $\mathrm{pH}$ value was adjusted to 7 to carry out crosslinking reaction, and thus kept DOX inside the nanoparticles. After three cycles of dispersion-centrifugation in water $(\mathrm{pH}=7)$ and vacuum drying, DOX-loading nanoparticles (DOX@HMS@P(NIPAM-co-DMA-Fe ${ }^{3+}$ )) were achieved.

The amount of free DOX in the collected supernatant was measured by the wavelength quantitative method using a UV spectrometer (Lambda $750 \mathrm{UV} / \mathrm{vis}$ ) at $480 \mathrm{~nm}$. The entrapment efficiency (EE) and loading capacity (LC) were calculated while using the following equations:

$$
\begin{aligned}
& \mathrm{EE}=\left[\left(m_{0}-m^{\prime} / m_{0}\right] \times 100 \%\right. \\
& \mathrm{LC}=\left[\left(m_{0}-m^{\prime} / m_{1}\right] \times 100 \%\right.
\end{aligned}
$$


where $m_{0}$ and $m^{\prime}$ are the total mass of DOX and the mass of free DOX, respectively; $m_{1}$ is the mass of nanoparticle.

Controlled release behavior was analyzed, as follows: DOX@HMS@P(NIPAM-co-DMA-Fe ${ }^{3+}$ ) (10 mg) was firstly dispersed in $1 \mathrm{~mL}$ of PBS and then transferred into a dialysis bag (molecular weight cut off $=14000$ ). Afterwards, the dialysis bag was kept in $49 \mathrm{~mL}$ of PBS with various temperatures $\left(26^{\circ} \mathrm{C}\right.$ and $\left.37^{\circ} \mathrm{C}\right)$ and $\mathrm{pH}(4.5,6.0$, and 7.4$)$, which was placed in a water-bathing constant temperature vibrator (150 rev $\mathrm{min}^{-1}$ ). At timed intervals, $5 \mathrm{~mL}$ of PBS buffer solution was sampled and analyzed by UV-vis. To keep a constant volume, $5 \mathrm{~mL}$ of fresh buffer was added after each sampling. All of the drug release results were averaged with three measurements.

\section{Results}

\subsection{Optimizing the Synthesis of HMS}

PS microspheres with various average diameter were firstly obtained by varying the mass ratio of PVP dispersant to St monomer. The particle size increase with decreasing mass ratio from 0.6 to 0.3 , which are 145, 212, and $285 \mathrm{~nm}$, as demonstrated by SEM (Figure 2a-c). Moreover, hydrodynamic diameters characterized by DLS are slightly larger than those of SEM [26,33]. Figure $2 \mathrm{~d}$ shows that they are $203.9 \pm 3.5,254.3 \pm 4.1$, and $319.3 \pm 4.2 \mathrm{~nm}$, respectively. The above results imply that the resultant PS microspheres have uniform particle size, smooth surface, and good mono-dispersity (polydispersity index of three kinds of PS microspheres are $0.005 \pm 0.0008,0.006 \pm 0.0007$, and $0.005 \pm$ 0.001 , respectively) [34,35].
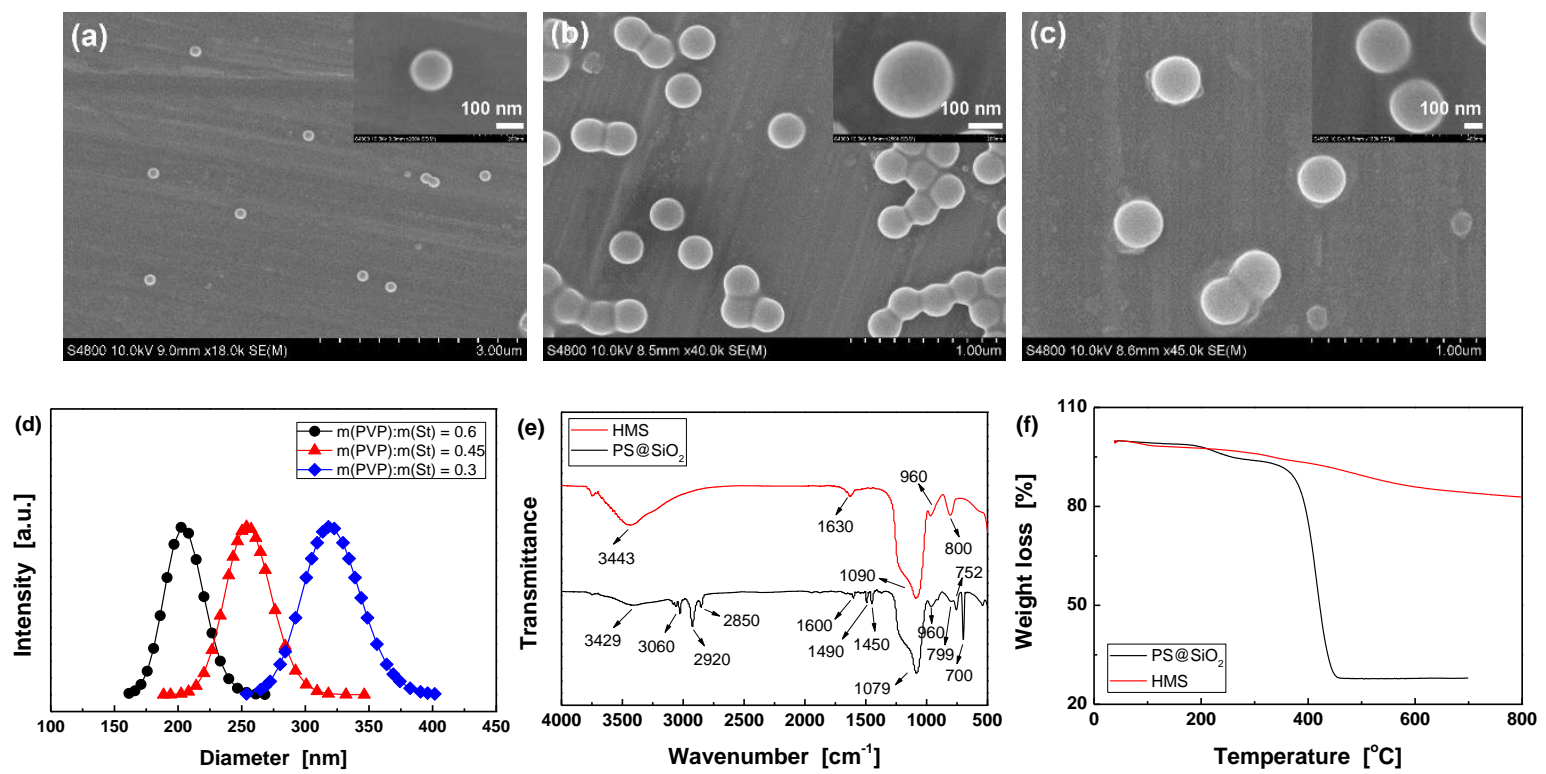

Figure 2. Scanning electron microscopy (SEM) images of polystyrene (PS) microspheres prepared at different mass ratio of polyvinylpyrrolidone (PVP) to St, (a) 0.6, (b) 0.45, (c) 0.3; The insets are enlarged images; The scale bars are $100 \mathrm{~nm}$; (d) Hydrodynamic diameters of PS microspheres; (e) FT-IR spectra; and, (f) Temperature Gravimetric Analysis (TGA) curves of $\mathrm{PS} @ S i O_{2}$ and $\mathrm{HMS}$ (preparation conditions: $\mathrm{m}(\mathrm{CTAB}): \mathrm{m}(\mathrm{TEOS}): \mathrm{m}(\mathrm{PS})=0.5: 1: 1)$.

As compared to PS@SiO ${ }_{2}$, the FTIR spectrum of HMS shows no characteristic peaks of organic compounds (Figure 2e), and there is only a small amount of weight loss in its TGA curve due to the dehydration of active hydroxyl groups on the surface of HMS (Figure 2f). The FTIR (Figure 2e) and TGA (Figure 2f) results both proved that the PS core and CTAB micelles in the shell were successfully removed after calcination [28,34]. Moreover, the XRD pattern of HMS in Figure S1 only exhibits a board diffraction peak centered at $2 \theta=2.46^{\circ}$, corresponding to a repeating unit (i.e., pore spacing) 
of $3.59 \mathrm{~nm}$ [26]. It suggests the existence of mesopores with lower degree of order in the walls of the spheres, which is in agreement with the reported results [21,26,36]. Meanwhile, HMS also display a wide dispersion peak at $2 \theta=20 \sim 30^{\circ}$ that belongs to amorphous $\mathrm{SiO}_{2}$ nanoparticles $[28,36]$. SEM and TEM observations (Figure 3) indicate the excellent particle uniformity and the typical silica shell comprised of the mesoporous structure. Furthermore, the electron contrast between the cores and the shells in the high-resolution TEM images confirms the formation of hollow particles.
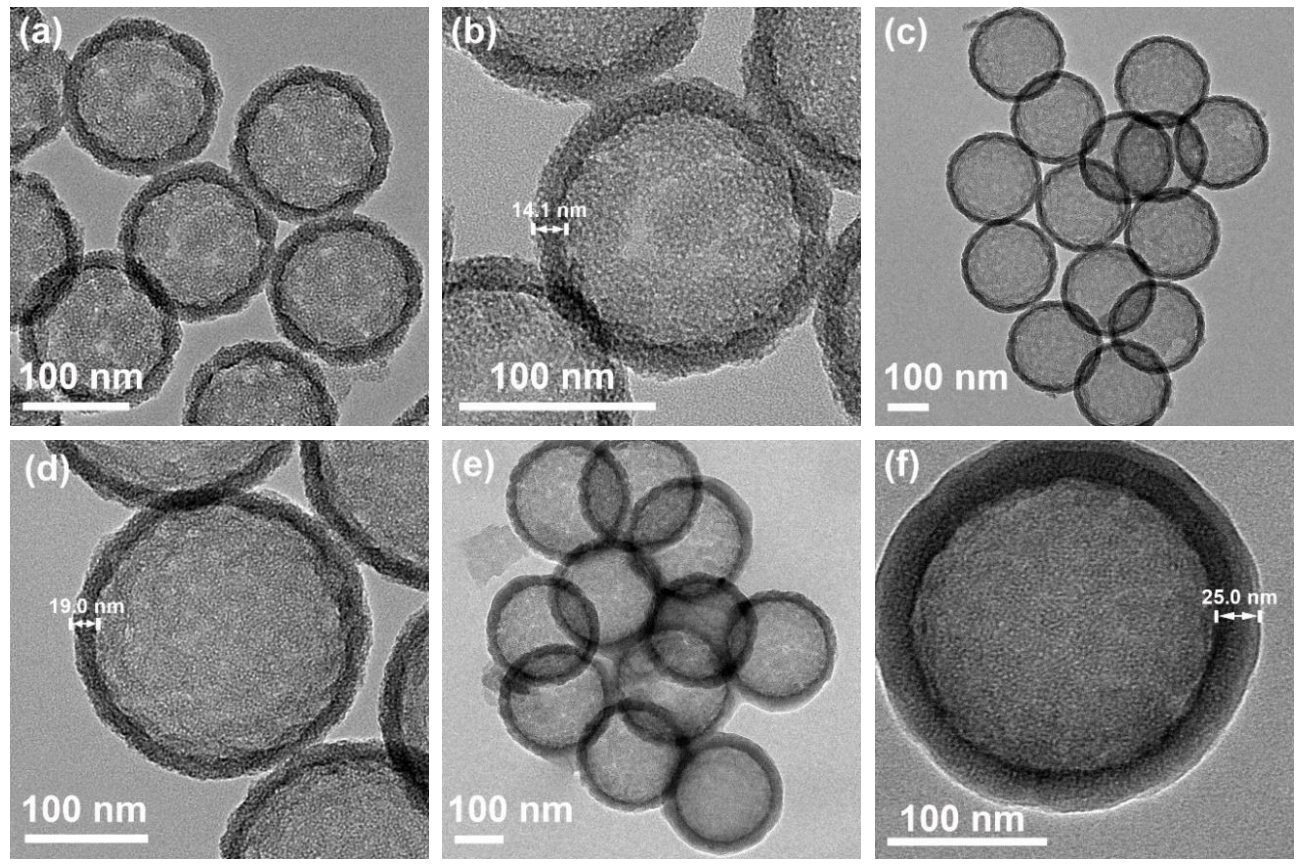

Figure 3. Transmission electron microscope (TEM) images of HMS obtained from $145 \mathrm{~nm}(\mathbf{a}, \mathbf{b})$ and 212 $\mathrm{nm}(\mathbf{c}, \mathbf{d})$ PS template microsphere, respectively; Preparation conditions: $\mathrm{m}(\mathrm{CTAB}): \mathrm{m}(\mathrm{TEOS}): \mathrm{m}(\mathrm{PS})=$ 0.5:1:1; (e,f) TEM image of HMS@P(NIPAM-co-DMA) obtained from (c,d).

Moreover, monodispersed HMS with a tunable particle size and shell thickness were successfully achieved by varying diameter of PS microsphere and TEOS content. With $145 \mathrm{~nm}$ and $212 \mathrm{~nm}$ PS microspheres as templates, it is found that the diameters of resultant HMS are $157 \mathrm{~nm}$ and $245 \mathrm{~nm}$ (Figure S2a,b) when the mass ratio of PS to TEOS is 1 (i.e., $\mathrm{m}(\mathrm{TEOS}): \mathrm{m}(\mathrm{PS})=1$ ). High-resolution TEM images (Figure 3a-d) further identify that the diameters are $152 \mathrm{~nm}$ and $228 \mathrm{~nm}$ and the shell thicknesses are $14.1 \mathrm{~nm}$ and $19.0 \mathrm{~nm}$, respectively. When TEOS content was increased to 1.5 times of PS (i.e., $\mathrm{m}(\mathrm{TEOS}): \mathrm{m}(\mathrm{PS})=1.5$ ), the shell thickness of HMS while using PS template with a diameter of $212 \mathrm{~nm}$ is more than $40 \mathrm{~nm}$, which is estimated from the diameter obtained by SEM (Figure S2c). It is consistent with the previous studies of HMS based on PS-co-PVP microsphere [28].

Meanwhile, the content of $\mathrm{CTAB}$ plays an important role in controlling the morphologies, specific surface area $\left(S_{B E T}\right)$, and total pore volume $\left(V_{t o t}\right)$ of HMS. Figure 4 reveals a type IV physisorption isotherm with an increase in nitrogen uptake at a high relative pressure $\left(\mathrm{p} / \mathrm{p}_{0}\right) 0.9-1.0$ and a hysteresis loop at $\mathrm{p} / \mathrm{p}_{0} 0.8-1.0$, indicating that HMS possesses a mesoporous structure [37,38]. The corresponding pore size distribution curves show a narrow pore distribution with a mean value of $2.2 \sim 2.3 \mathrm{~nm}$. When the mass ratios of CTAB to TEOS is 0.5 , the specific surface area and the average pore diameter are estimated to be about $866 \mathrm{~m}^{2} \mathrm{~g}^{-1}$ and $2.3 \mathrm{~nm}$ while using the BET and BJH methods, respectively. The specific surface area is comparable to, or even superior to, the similar product, as reported in these literatures $[28,39]$. In the mass ratio ranging from 0 to 0.9 , the increase of CTAB could improve the specific surface area $\left(144 \sim 895 \mathrm{~m}^{3} \mathrm{~g}^{-1}\right)$ and total pore volume $\left(0.072 \sim 1.482 \mathrm{~cm}^{3} \mathrm{~g}^{-1}\right)$, but it has little effect on the pore diameter (Table S1). The regulatory functions of CTAB shown above are consistent with previous studies [40]. 

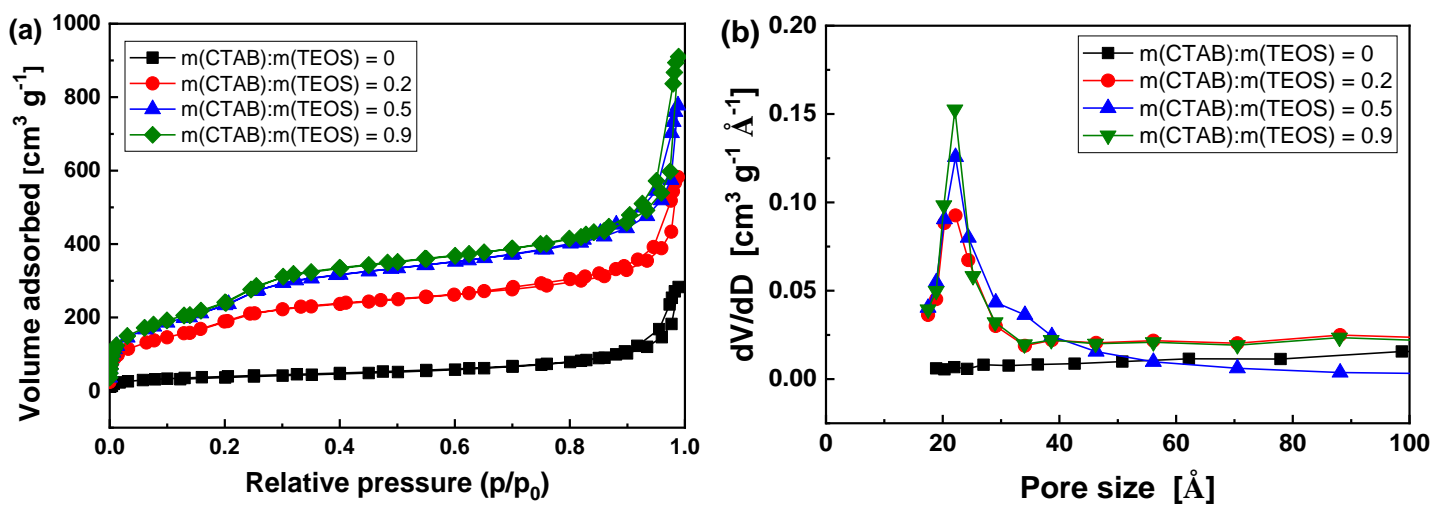

Figure 4. Nitrogen adsorption-desorption isotherms (a) and the pore size (b) of HMS prepared with various ratio of hexadecyl trimethyl ammonium bromide (CTAB) and tetraethoxysilane (TEOS).

\subsection{Preparation of HMS@P(NIPAM-co-DMA)}

Before incorporating temperature and $\mathrm{pH}$ responsive functional copolymer into HMS nanospheres, HMS with a diameter of $245 \mathrm{~nm}$ (Figure 3c,d) was modified by silane coupling agent KH570 to introduce reactive double bonds. The obvious vibration absorptions of methyl and methylene in the range of $2800 \sim 3000 \mathrm{~cm}^{-1}$ and carbonyl at $1710 \mathrm{~cm}^{-1}$ indicate that KH570 has been successfully grafted onto HMS surface (Figure 4a) [41]. Subsequently, KH570 modified HMS was used as the seed and copolymerized with NIPAM and DMA. Accordingly, in the resulting product, the $\mathrm{C}=\mathrm{O}$ stretching $\left(1650 \mathrm{~cm}^{-1}\right)$ and $\mathrm{N}-\mathrm{H}$ bending $\left(1540 \mathrm{~cm}^{-1}\right)$ vibration absorptions of amide group in NIPAM [42], as well as $\mathrm{C}=\mathrm{O}$ stretching $\left(1720 \mathrm{~cm}^{-1}\right)$ vibration absorption of ester group in DMA, can be observed, which implies the successful grafting of Poly(NIPAM-co-DMA) on the surface of HMS (Figure 4a). Furthermore, ${ }^{1} \mathrm{H}$ NMR detected the chemical structure of copolymer after the removal of HMS component by treating with 20 vol.\% hydrofluoric acid solution. As shown in Figure $4 \mathrm{~b}$, it shows all of the proton chemical shifts of the copolymers.

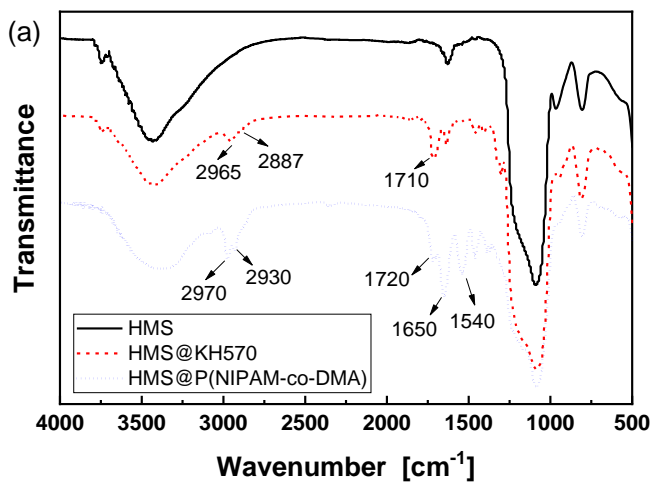

(b)
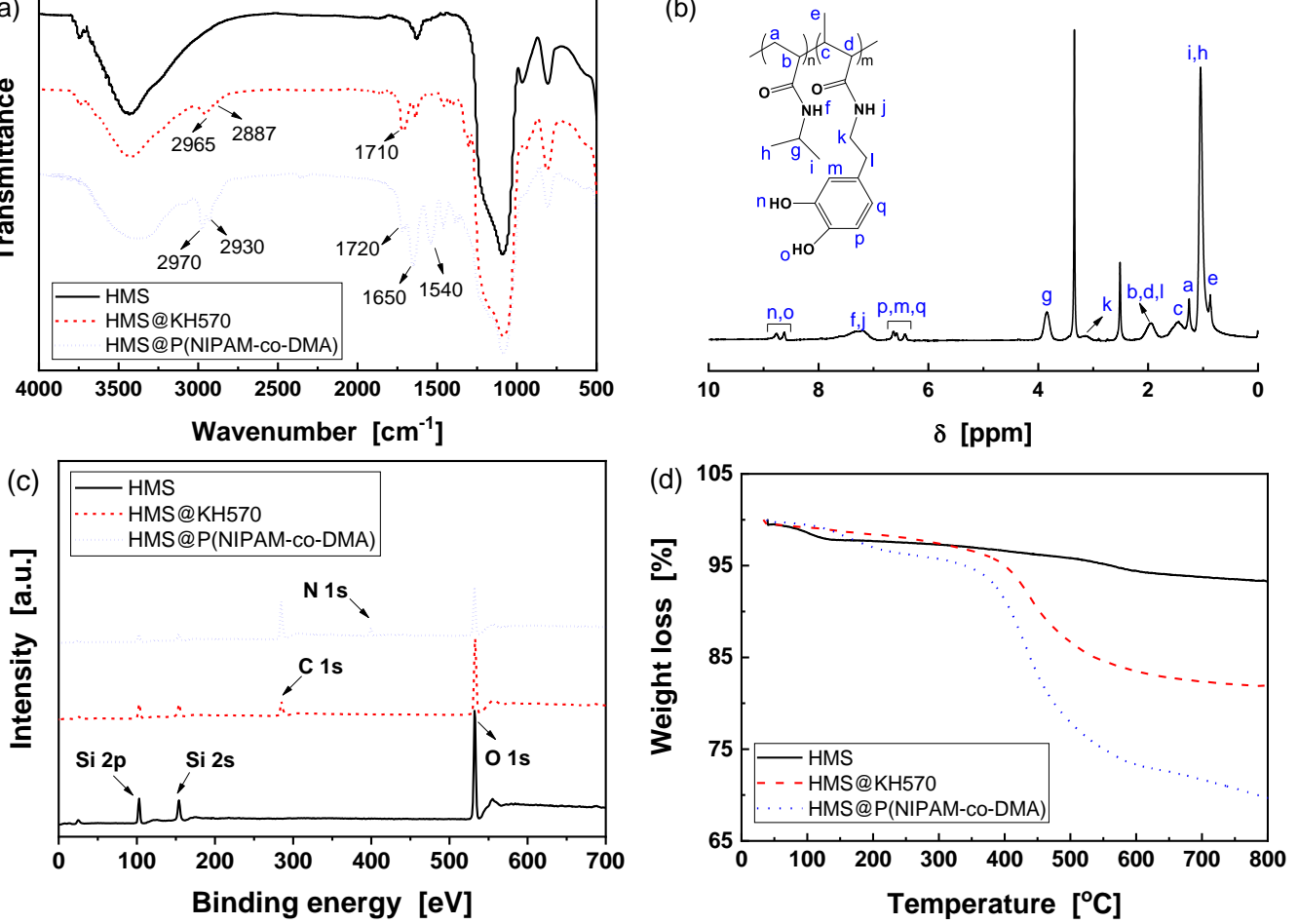

Figure 4. Cont. 


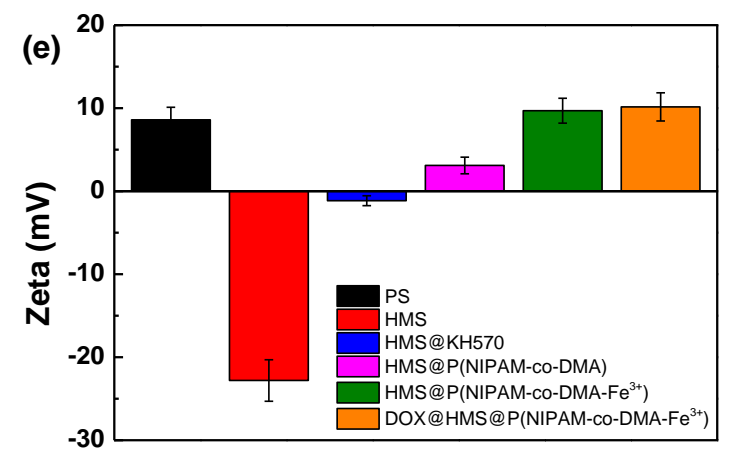

Figure 4. (a) FT-IR, (b) ${ }^{1} \mathrm{H}$ NMR, (c) X-ray photoelectron spectroscopy (XPS), (d) TGA spectra and (e) zeta potentials of HMS, HMS@KH570 and HMS@P(NIPAM-co-DMA).

XPS analysis can provide insights into the chemical compositions of polymer shell [43]. Figure 4c shows the chemical identification of the surfaces of HMS, HMS@KH570 and HMS@P(NIPAM-co-DMA). The full spectrum reveals the presence of $\mathrm{Si} 2 \mathrm{~s}, \mathrm{Si} 2 \mathrm{p}$, and $\mathrm{O} 1 \mathrm{~s}$ emissions with binding energies at 154,105 , and $533 \mathrm{eV}$ on the surface of HMS. After modification with KH570, the C 1s hydrocarbon peak at $285 \mathrm{eV}$ is observed. With respect to HMS@P(NIPAM-co-DMA), the relative intensity of C 1 s peak obviously increases, and a new peak at $399 \mathrm{eV}$ corresponding to $\mathrm{N} 1$ s generated from the copolymer shell is obtained, which implies that NIPAM and DMA monomers were chemically grafted on HMS surface.

Subsequently, the zeta potentials of the as-prepared nanoparticles and DOX loaded HSM were measured. The results (Figure 4e) indicate that HMS possesses a negative zeta potential due to the strong electronegativity of $\mathrm{Si}-\mathrm{OH}$ groups on the surface of nanoparticles. After grafting of $\mathrm{KH}-570$, the $\mathrm{Si}-\mathrm{OH}$ groups were reacted, leading to a low negative zeta potential. With the further incorporating of $\mathrm{P}$ (NIPAM-co-DMA) copolymer and $\mathrm{Fe}^{3+}$ ions, the zeta potential gradually becomes positive. It may be attributed to the fact that the copolymer and $\mathrm{Fe}^{3+}$ ions possess positive charge.

The weight loss of different nanoparticles in the range of $50 \sim 800{ }^{\circ} \mathrm{C}$ were measured by TGA in order to quantitatively determine the amount of grafted polymer (Figure 4d), and Table 1 summarizes the results. All of the samples present two stages of weight loss. For HMS, the weight loss stage below $250{ }^{\circ} \mathrm{C}$ is attributed to the evaporation of physically adsorbed water and residual solvent, while the decomposition of the silica-bonded hydroxyl and alkyl groups must be responsible for that between $250 \sim 800{ }^{\circ} \mathrm{C}[28,44]$. After the grafting of copolymer, the latter weight loss stage of HMS@KH570 and HMS@P(NIPAM-co-DMA) increase from 4.1\% of HMS to $16.2 \%$ and $26.4 \%$, respectively. According to Equation (1), the grafting yields of KH570 and P(NIPAM-co-DMA) copolymer are estimated to be $14.8 \%$ and $14.6 \%$, respectively. The free radical polymerization that was utilized in this work is a common method for introducing polymer on silica surface, but the grafting efficiency is relatively lower. As compared with grafting polymers that were obtained from ATRP and RAFT [45,46], the dispersity of the as-prepared $\mathrm{P}$ (NIPAM-co-DMA) random copolymer is higher, but the preparation condition is simpler.

Table 1. TGA results and grafting yield for various nanoparticles obtained from Figure 4d.

\begin{tabular}{ccccc}
\hline Sample & $\begin{array}{c}\text { Weight Loss < } \\
\mathbf{2 5 0}{ }^{\circ} \mathbf{C ~ [ \% ] ~}\end{array}$ & $\begin{array}{c}\text { Weight Loss at } \\
\mathbf{2 5 0 ~} \mathbf{8 0 0}{ }^{\circ} \mathbf{C ~ [ \% ] ~}\end{array}$ & $\begin{array}{c}\text { Residue Weight } \\
{[\%]}\end{array}$ & Grafting Yield [\%] \\
\hline HMS & 2.5 & 4.1 & 93.4 & - \\
HMS@KH570 & 2.0 & 16.2 & 81.8 & 14.8 \\
HMS@P(NIPAM-co-DMA) & 3.9 & 26.4 & 69.7 & 14.6 \\
\hline
\end{tabular}

The morphology and structure of the as-synthesized copolymer-grafted HMS was examined by means of TEM (Figure 3e,f), which confirmed the particle uniformity and typical core-shell structure. 
The results show that the diameter and shell thickness increase from 228 and $19.0 \mathrm{~nm}$ (Figure 3d) of HMS to 250 and $25.0 \mathrm{~nm}$, respectively.

\subsection{DOX Loading and Controlled Release in Vitro}

Generally, the size of drug molecules should be smaller than the diameter of mesopore channels to achieve the effective storage and release of drugs in hollow mesoporous silica nanoparticles [47]. As one of the most potent anticancer drugs [48], DOX was applied as a model drug to evaluate the loading and controlled release properties of the modified HMS. The loading process of DOX is mainly based on the physical adsorption mechanism in mesoporous channels. In general, the incorporation of DOX was achieved by soaking HMS@P(NIPAM-co-DMA-Fe ${ }^{3+}$ ) nanoparticles in a DOX/PBS solution at a $\mathrm{pH}$ value of 4.5 for $48 \mathrm{~h}$, accompanied by magnetic stirring to favor the diffusion of drug molecules through the mesoporous shell into the cavity. The intensities of vibration peaks at about $3444(-\mathrm{OH}$ and $\left.-\mathrm{NH}_{2}\right)$ and $1720 \mathrm{~cm}^{-1}(\mathrm{C}=\mathrm{O})$ correspondingly increase for the loaded particles since the DOX molecule contains a large number of hydroxyl $(-\mathrm{OH})$, amino $\left(-\mathrm{NH}_{2}\right)$ and carbonyl $(\mathrm{C}=\mathrm{O})$ groups [49] (Figure 5a). Moreover, a new peak at $1580 \mathrm{~cm}^{-1}$ belonging to stretching vibration of $-\mathrm{NH}_{2}$ is observed, which also implies that DOX was successfully loaded. Moreover, the zeta potential of DOX-loaded nanoparticle (about $10.2 \mathrm{mV}$ ) was almost the same as that of HMS@P(NIPAM-co-DMA-Fe $\left.{ }^{3+}\right)(9.7 \mathrm{mV})$. In the loading process of DOX, the $\mathrm{pH}$ value was adjusted to 7 by hydrochloric acid finally, so the DOX molecule was electric neutral and it had little effect on zeta potential.
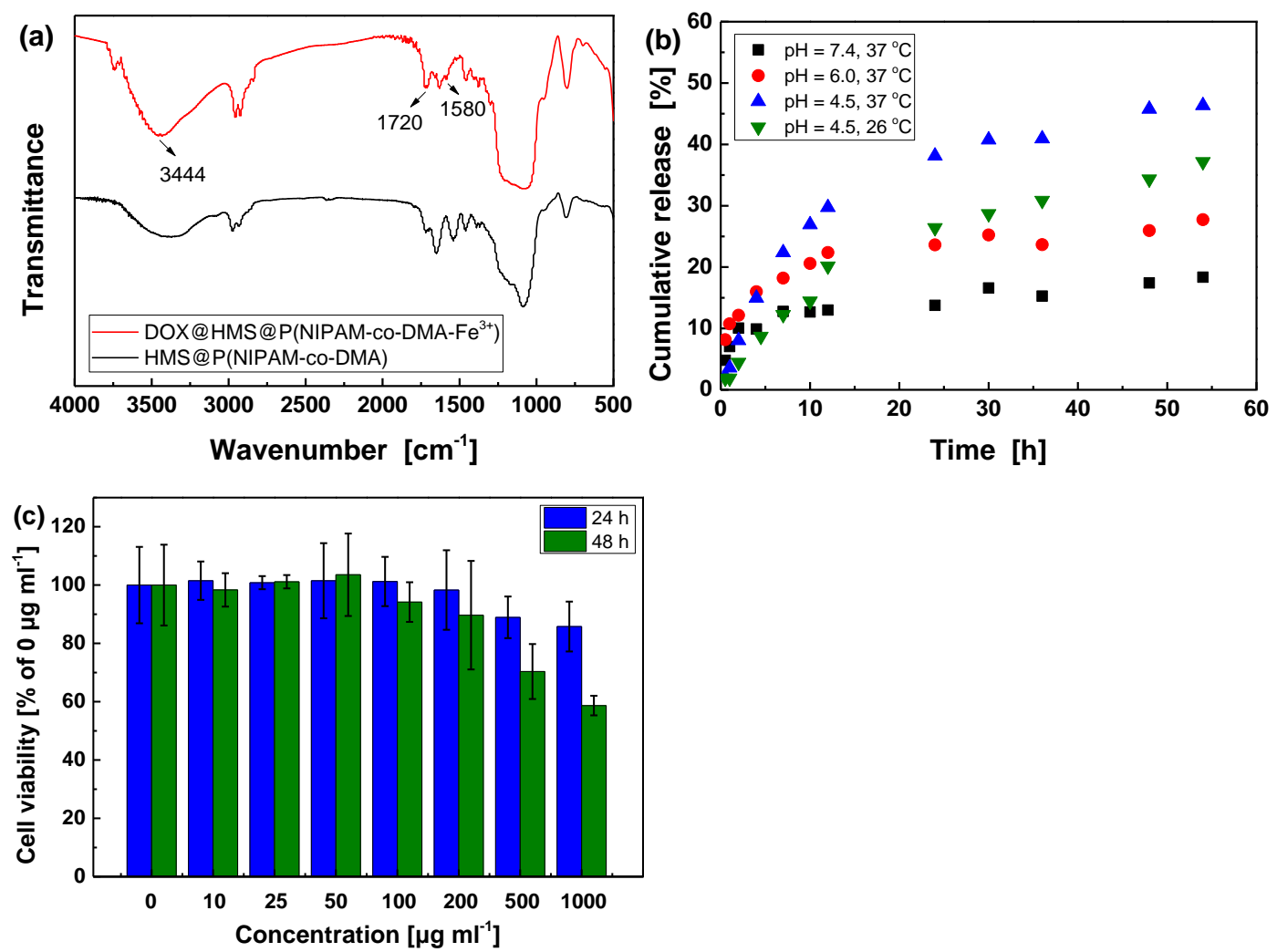

Figure 5. (a) FT-IR spectra of HMS@P(NIPAM-co-DMA) and DOX@HMS@P(NIPAM-co-DMA-Fe ${ }^{3+}$ ); (b) Cumulative release of DOX from DOX@HMS@P(NIPAM-co-DMA-Fe ${ }^{3+}$ ) nanoparticles in different conditions; (c) Cell viability of RAW 264.7 cells treated with different concentrations of HMS@P(NIPAM-co-DMA-Fe ${ }^{3+}$ ) for $24 \mathrm{~h}$ and $48 \mathrm{~h}$.

Subsequently, the entrapment efficiency (EE), loading capacity (LC), mass percentage of drug were analyzed according to UV-vis standard curve (Figure S6) and Equations (2) and (3). As shown in Table 2, they are calculated to be $94.6 \%, 9.5 \mathrm{wt} \%$, and $8.6 \mathrm{wt} \%$ under $1 \mathrm{mg} \mathrm{ml}^{-1}$ DOX/PBS solution, 
respectively. Importantly, the results show that the grafting polymer shell did not significantly affect the loading capacity of porous microspheres in comparation with unmodified HMS. Moreover, the TGA curves (Figure S7) also validate that the weight percentage of the drug is about $8.0 \mathrm{wt} \%$, which is in agreement with the results of UV-vis experiment. In fact, the mass percentage of drug can be easily improved to as high as $28.0 \%$ by increasing the DOX concentration (e.g., $5 \mathrm{mg} \mathrm{ml}^{-1}$, Figure S7). The loading capacity and entrapment efficiency of modified HMS can both be comparable to the reported results by Yang and coworkers [50].

Table 2. Comparisons of drug loading properties under $1 \mathrm{mg} \mathrm{ml}^{-1}$ DOX/PBS solution calculated from Figures S6 and S7.

\begin{tabular}{cccccc}
\hline Sample & $\begin{array}{c}\text { Drug Loading } \\
\mathbf{1}[\mathbf{m g}]\end{array}$ & $\begin{array}{c}\text { Loading } \\
\text { Capacity } \\
\text { (LC) [\%] }\end{array}$ & $\begin{array}{c}\text { Mass } \\
\text { Percentage } \\
\mathbf{1}_{[\%]}\end{array}$ & $\begin{array}{c}\text { Entrapment } \\
\text { Efficiency }{ }^{1} \\
\text { (EE) [\%] }\end{array}$ & $\begin{array}{c}\text { Mass } \\
\text { Percentage } \\
\mathbf{2}^{[\%]}\end{array}$ \\
\hline HMS & 4.70 & 9.4 & 8.5 & 94.0 & 8.1 \\
HMS@P(NIPAM-co-DMA-Fe ${ }^{3+}$ ) & 4.73 & 9.5 & 8.6 & 94.6 & 8.0 \\
\hline
\end{tabular}

${ }^{1}$ obtained from UV-vis standard curves; ${ }^{2}$ obtained from TGA curves.

As shown in Figure 5b, the DOX release experiments were performed in PBS solution with various conditions to evaluate the $\mathrm{pH}$ and thermo-sensitivity of biomimetic HMS@P(NIPAM-co-DMA-Fe ${ }^{3+}$ ) nanoparticles. In the drug release process, DOX must diffuse across the polymer shell limited by crosslinked density and phase state of grafted polymers. Consequently, it is noticed that the release of DOX at $37^{\circ} \mathrm{C}$ is effectively accelerated as the $\mathrm{pH}$ of the PBS buffer decreases. The release of DOX at $\mathrm{pH}$ values of $4.5,6.0$ and 7.4 for $48 \mathrm{~h}$ reach $45.8 \%, 30.0 \%$, and $17.4 \%$, respectively. It has been widely verified that the mono-, bis-, and tris-coordinated catechol- $\mathrm{Fe}^{3+}$ complexes form in turn when the $\mathrm{pH}$ is gradually increased from about 4 to $9[22,23]$. Since the crosslinking degree between the grafted copolymerization chains is controlled by the $\mathrm{pH}$-sensitive catechol-Fe ${ }^{3+}$ coordination bonds, it consistently decreases with the decreasing of $\mathrm{pH}$ value, resulting in faster diffusion and release of drug within the same period of time.

Moreover, $37^{\circ} \mathrm{C}$ and $26^{\circ} \mathrm{C}$, being slightly higher and lower than LCST $\left(32^{\circ} \mathrm{C}\right)$ of the PNIPAM, were chosen to verify the temperature response behavior. The cumulative release of DOX within $48 \mathrm{~h}$ at $37^{\circ} \mathrm{C}$ and $\mathrm{pH}$ value of 4.5 (i.e., $45.8 \%$ ) is higher than that at $26^{\circ} \mathrm{C}$ (i.e., $37.2 \%$ ). The DOX release rate increase with temperature is ascribed to the shrunken state of the PNIPAM polymer shell and small hydrodynamic diameter above LCST, which is conductive to exposing the pore channels of HMS and shortening the diffusion pathways for faster release [21]. Hence, if these nanocarriers accumulate at a focus of infection with lower $\mathrm{pH}$ and elevated temperature, a faster local drug release might be expected [50]. For comparison, the reference sample DOX@HMS without polymer shell exhibits obvious burst release characteristics, which release $43.4 \%$ of DOX within $0.5 \mathrm{~h}$ (Figure S8). Drug release studies in vitro show that the release behavior is $\mathrm{pH}$ and temperature-responsive, and comparable to other reported drug delivery system $[49,51]$, displaying the potential application prospects in the field of drug sustained release. However, the biocompatibility and antitumorigenic effect need to be carefully studied in the future.

\subsection{In Vitro Cytotoxicity Assay}

The cytotoxicity of nanoparticles is a crucial issue for their controlled drug release applications. [49] For evaluating cytotoxicity of the as-prepared HMS@P(NIPAM-co-DMA-Fe ${ }^{3+}$ ), cell viability was measured by MTT assay. As shown in Figure $5 c$, when the incubation time is $24 h$, the survival of the treated RAW 264.7 cells was more than $85 \%$ relative to the untreated cells, even at $1000 \mu \mathrm{g} \mathrm{ml}^{-1}$ of HMS@P(NIPAM-co-DMA-Fe ${ }^{3+}$ ). With the extending of incubation time to $48 \mathrm{~h}$, the viability of cells treated with high concentration of HMS@P(NIPAM-co-DMA-Fe ${ }^{3+}$ ) (e.g., $>500 \mu \mathrm{g} \mathrm{ml}^{-1}$ ) decreases sharply, but the cell viability remains over $90 \%$ within $100 \mu \mathrm{g} \mathrm{ml}^{-1}$ of nanoparticles. The results 
indicate that HMS@P(NIPAM-co-DMA-Fe ${ }^{3+}$ ) nanoparticles have no significant cytotoxicity on RAW 264.7 cells, and they present good biocompatibility as drug carriers. It is in a good agreement with the previous results of the low cytotoxicity of nanospheres based on silica, PNIPAM, and polydopamine, respectively. $[24,25,52,53]$

\section{Conclusions}

In summary, a biomimetic composite microsphere with HMS core and P(NIPAM-co-DMA) shell was firstly prepared. Especially, with the addition of $\mathrm{Fe}^{3+}$, the polymer shell of HMS@P(NIPAM-co-DMA) can be crosslinked by catechol-Fe ${ }^{3+}$ coordination bonds. As a result, the polymer shell possesses both temperature and $\mathrm{pH}$ sensitivity, which is dependent on dissociation/association of the coordination bonds combining with phase transition behavior of PNIPAM. DOX was applied as a model drug for evaluating the loading and controlled release properties. The results demonstrated that this composite microsphere had a significant drug loading capacity of $8.84 \%$ and embed efficiency of $94.60 \%$ under $1 \mathrm{mg} \mathrm{m}^{-1}$ DOX/PBS solution. The cumulative release of DOX in vitro $\left(37^{\circ} \mathrm{C}\right)$ showed low leakage $(17.4 \%)$ at a $\mathrm{pH}$ value of 7.4 , but it was significantly enhanced to $45.8 \%$ at the $\mathrm{pH}$ value of 4.5 . Moreover, the cumulative release at $37^{\circ} \mathrm{C}$ is faster than that at $26^{\circ} \mathrm{C}$. The vitro cytotoxicity assay also indicated that the as-prepared nanoparticles have no significant cytotoxicity on RAW 264.7 cells. These results demonstrated that the drug release was apparently environmentally responsive and has potential application in controlled drug release.

Supplementary Materials: The following are available online at http://www.mdpi.com/2073-4360/11/11/1832/s1, Figure S1: Powder XRD patterns of HMS, Figure S2: SEM images of HMS obtained from $145 \mathrm{~nm}$ (a) and 212 nm (b) PS template microsphere, Figure S3: FT-IR spectra of DMA, Figure S4: ${ }^{1} \mathrm{H}$ NMR spectra of DMA in DMSO-d6, Figure S5: ${ }^{13} \mathrm{C}$ NMR spectra of DMA in DMSO-d6, Figure S6: The standard curve of DOX obtained from ultraviolet absorption at $480 \mathrm{~nm}$ in the concentration range of $0 \sim 10 \mu \mathrm{g} \mathrm{ml}^{-1}$ (a) and $20 \sim 90 \mu \mathrm{g} \mathrm{ml}^{-1}$ (b), Figure S7: TGA curves of (a) DOX@HMS@P(NIPAM-co-DMA) and un-modified HMS (b) obtained from DOX/PBS with different concentrations, Figure S8: Cumulative release of DOX from DOX@HMS, Scheme S1: The synthesis mechanism of DMA, Table S1: Structure properties of HMS prepared with various ratio of CTAB and TEOS.

Author Contributions: Data curation, W.P., Z.Z. and M.R.; Investigation, W.P.; Methodology, M.R. and M.Z.; Writing-original draft, W.P. and Z.Z.; Writing-review \& editing, Z.Z., M.R. and M.Z.; Funding acquisition, Z.Z., M.R. and M.Z.

Funding: This research was funded by National Natural Science Foundation of China (grant number 51603235, 51673219, 51773229 and 51873235), the Scientific and Technological Program of Guangdong Province (grant number: 2017A010103008), Natural Science Foundation of Guangdong Province (grant number: 2018B030311017) and the Fundamental Research Funds for the Central Universities (grant number: 181gpy41).

Conflicts of Interest: The authors declare no conflict of interest.

\section{References}

1. Yavvari, P.S.; Pal, S.; Kumar, S.; Kar, A.; Awasthi, A.K.; Naaz, A.; Srivastava, A.; Bajaj, A. Moldable and removable wound dressing based on dynamic covalent cross-linking of thiol-aldehyde addition. ACS Biomater. Sci. Eng. 2017, 3, 3404-3413. [CrossRef]

2. Wang, Z.; Deng, X.; Ding, J.; Zhou, W.; Zheng, X.; Tang, G. Mechanisms of drug release in pH-sensitive micelles for tumour targeted drug delivery system: A review. Int. J. Pharm. 2018, 535, 253-260. [CrossRef] [PubMed]

3. Riaz, M.; Zhang, X.; Lin, C.; Wong, K.H.; Chen, X.; Zhang, G.; Lu, A.; Yang, Z.; Riaz, M.K.; Riaz, M.A. Surface Functionalization and Targeting Strategies of Liposomes in Solid Tumor Therapy: A Review. Int. J. Mol. Sci. 2018, 19, 195. [CrossRef] [PubMed]

4. Pugazhendhi, A.; Edison, T.N.J.I.; Karuppusamy, I.; Kathirvel, B. Inorganic nanoparticles: A potential cancer therapy for human welfare. Int. J. Pharm. 2018, 539, 104-111. [CrossRef]

5. Vallet-Regí, M.; Colilla, M.; Gonzalez, B. Medical applications of organic-inorganic hybrid materials within the field of silica-based bioceramics. Chem. Soc. Rev. 2011, 40, 596-607. [CrossRef]

6. Chen, J.-F.; Ding, H.-M.; Wang, J.-X.; Shao, L. Preparation and characterization of porous hollow silica nanoparticles for drug delivery application. Biomaterials 2004, 25, 723-727. [CrossRef] 
7. Li, Y.; Shi, J. Hollow-Structured Mesoporous Materials: Chemical Synthesis, Functionalization and Applications. Adv. Mater. 2014, 26, 3176-3205. [CrossRef]

8. Torchilin, V.P. Multifunctional nanocarriers. Adv. Drug Deliv. Rev. 2006, 58, 1532-1555. [CrossRef]

9. Hartono, S.B.; Phuoc, N.T.; Yu, M.; Jia, Z.; Monteiro, M.J.; Qiao, S.Z.; Yu, C. Functionalized large pore mesoporous silica nanoparticles for gene delivery featuring controlled release and co-delivery. J. Mater. Chem. B 2014, 2, 718-726. [CrossRef]

10. Spange, S. Silica surface modification by cationic polymerization and carbenium intermediates. Prog. Polym. Sci. 2000, 25, 781-849. [CrossRef]

11. Bull, S.D.; Davidson, M.G.; Elsen, J.M.H.V.D.; Fossey, J.S.; Jenkins, A.T.A.; Jiang, Y.-B.; Kubo, Y.; Marken, F.; Sakurai, K.; Zhao, J.; et al. Exploiting the Reversible Covalent Bonding of Boronic Acids: Recognition, Sensing, and Assembly. Acc. Chem. Res. 2012, 46, 312-326. [CrossRef] [PubMed]

12. Luo, Z.; Cai, K.; Hu, Y.; Zhao, L.; Liu, P.; Duan, L.; Yang, W. Mesoporous silica nanoparticles end-capped with collagen: Redox-responsive nanoreservoirs for targeted drug delivery. Angew. Chem. 2011, 50, $640-643$. [CrossRef] [PubMed]

13. Yang, J.; Shen, D.; Zhou, L.; Li, W.; Li, X.; Yao, C.; Wang, R.; El-Toni, A.M.; Zhang, F.; Zhao, D. Spatially Confined Fabrication of Core-Shell Gold Nanocages@Mesoporous Silica for Near-Infrared Controlled Photothermal Drug Release. Chem. Mater. 2013, 25, 3030-3037. [CrossRef]

14. Huang, S.-H.; Juang, R.-S. Biochemical and biomedical applications of multifunctional magnetic nanoparticles: A review. J. Nanopart. Res. 2011, 13, 4411-4430. [CrossRef]

15. Tannock, I.F.; Rotin, D. Acid pH in tumors and its potential for therapeutic exploitation. Cancer Res. 1989, 49, 4373-4384.

16. Van Der Stappen, J.W.J.; Williams, A.C.; Maciewicz, R.A.; Paraskeva, C. Activation of cathepsin B, secreted by a colorectal cancer cell line requires low $\mathrm{pH}$ and is mediated by cathepsin D. Int. J. Cancer 1996, 67, 547-554. [CrossRef]

17. Zhang, L.; Guo, R.; Yang, M.; Jiang, X.; Liu, B. Thermo and pH Dual-Responsive Nanoparticles for Anti-Cancer Drug Delivery. Adv. Mater. 2007, 19, 2988-2992. [CrossRef]

18. Kaga, S.; Truong, N.P.; Esser, L.; Senyschyn, D.; Sanyal, A.; Sanyal, R.; Quinn, J.F.; Davis, T.P.; Kaminskas, L.M.; Whittaker, M.R. Influence of Size and Shape on the Biodistribution of Nanoparticles Prepared by Polymerization-Induced Self-Assembly. Biomacromolecules 2017, 18, 3963-3970. [CrossRef]

19. Khor, S.Y.; Vu, M.N.; Pilkington, E.H.; Johnston, A.P.R.; Whittaker, M.R.; Quinn, J.F.; Truong, N.P.; Davis, T.P. Elucidating the Influences of Size, Surface Chemistry, and Dynamic Flow on Cellular Association of Nanoparticles Made by Polymerization-Induced Self-Assembly. Small 2018, 14, 1801702. [CrossRef]

20. Wang, D.; Huang, H.; Zhou, M.; Lu, H.; Chen, J.; Chang, Y.-T.; Gao, J.; Chai, Z.; Hu, Y. A thermoresponsive nanocarrier for mitochondria-targeted drug delivery. Chem. Commun. 2019, 55, 4051-4054. [CrossRef]

21. You, Y.-Z.; Kalebaila, K.K.; Brock, S.L.; Oupický, D. Temperature-Controlled Uptake and Release in PNIPAM-Modified Porous Silica Nanoparticles. Chem. Mater. 2008, 20, 3354-3359. [CrossRef]

22. Vaccaro, E.; Waite, J.H. Yield and post-yield behavior of mussel byssal thread: A self-healing biomolecular material. Biomacromolecules 2001, 2, 906-911. [CrossRef]

23. Xia, N.N.; Xiong, X.M.; Wang, J.; Rong, M.Z.; Zhang, M.Q. A seawater triggered dynamic coordinate bond and its application for underwater self-healing and reclaiming of lipophilic polymer. Chem. Sci. 2016, 7, 2736-2742. [CrossRef]

24. Lee, B.P.; Narkar, A.; Wilharm, R. Effect of metal ion type on the movement of hydrogel actuator based on catechol-metal ion coordination chemistry. Sens. Actuators B Chem. 2016, 227, 248-254. [CrossRef]

25. Gong, C.; Lu, C.; Li, B.; Shan, M.; Wu, G. Injectable dopamine-modified poly( $\alpha$, $\beta$-aspartic acid) nanocomposite hydrogel as bioadhesive drug delivery system. J. Biomed. Mater. Res. Part A 2017, 105, 1000-1008. [CrossRef]

26. Qi, G.; Wang, Y.; Estevez, L.; Switzer, A.K.; Duan, X.; Yang, X.; Giannelis, E.P. Facile and Scalable Synthesis of Monodispersed Spherical Capsules with a Mesoporous Shell. Chem. Mater. 2010, 22, 2693-2695. [CrossRef]

27. Zou, H.; Wu, S.; Ran, Q.; Shen, J. A Simple and Low-Cost Method for the Preparation of Monodisperse Hollow Silica Spheres. J. Phys. Chem. C 2008, 112, 11623-11629. [CrossRef]

28. Wang, S.; Zhang, M.; Wang, D.; Zhang, W.; Liu, S. Synthesis of hollow mesoporous silica microspheres through surface sol-gel process on polystyrene-co-poly(4-vinylpyridine) core-shell microspheres. Microporous Mesoporous Mater. 2011, 139, 1-7. [CrossRef] 
29. White, E.M.; Seppala, J.E.; Rushworth, P.M.; Ritchie, B.W.; Sharma, S.; Locklin, J. Switching the Adhesive State of Catecholic Hydrogels using Phototitration. Macromolecules 2013, 46, 8882-8887. [CrossRef]

30. Szunerits, S.; Boukherroub, R. Preparation and Characterization of Thin Films of SiOxon Gold Substrates for Surface Plasmon Resonance Studies. Langmuir 2006, 22, 1660-1663. [CrossRef]

31. Zhang, Y.; Chen, H.; Wen, Y.; Yuan, Y.; Wu, W.; Liu, C. Tunable wettability of monodisperse core-shell nano-SiO2 modified with poly(methylhydrosiloxane) and allyl-poly(ethylene glycol). Colloids Surf. A Physicochem. Eng. Asp. 2014, 441, 16-24. [CrossRef]

32. Chen, J.C.; Luo, W.Q.; Wang, H.D.; Xiang, J.M.; Jin, H.F.; Chen, F.; Cai, Z. A versatile method for the preparation of end-functional polymers onto $\mathrm{SiO}_{2}$ nanoparticles by a combination of surface-initiated ATRP and Huisgen [3 + 2] cycloaddition. Appl. Surf. Sci. 2010, 256, 2490-2495. [CrossRef]

33. Mishra, P.K.; Wimmer, R. Aerosol assisted self-assembly as a route to synthesize solid and hollow spherical lignin colloids and its utilization in layer by layer deposition. Ultrason. Sonochem. 2017, 35, 45-50. [CrossRef] [PubMed]

34. Lin, X.; Li, X.; Zheng, L.; Yu, L.; Zhang, Q.; Liu, W. Preparation and characterization of monocaprate nanostructured lipid carriers. Colloids Surf. A Physicochem. Eng. Asp. 2007, 311, 106-111. [CrossRef]

35. Blas, H.; Save, M.; Pasetto, P.; Boissière, C.; Sanchez, C.; Charleux, B. Elaboration of Monodisperse Spherical Hollow Particles with Ordered Mesoporous Silica Shells via Dual Latex/Surfactant Templating: Radial Orientation of Mesopore Channels. Langmuir 2008, 24, 13132-13137. [CrossRef]

36. Le, Y.; Chen, J.-F.; Wang, W.-C. Study on the silica hollow spheres by experiment and molecular simulation. Appl. Surf. Sci. 2004, 230, 319-326. [CrossRef]

37. Wu, X.; Tian, Y.; Cui, Y.; Wei, L.; Wang, Q.; Chen, Y. Raspberry-like Silica Hollow Spheres: Hierarchical Structures by Dual Latex-Surfactant Templating Route. J. Phys. Chem. C 2007, 111, 9704-9708. [CrossRef]

38. Zhu, Y.; Shi, J.; Chen, H.; Shen, W.; Dong, X. A facile method to synthesize novel hollow mesoporous silica spheres and advanced storage property. Microporous Mesoporous Mater. 2005, 84, 218-222. [CrossRef]

39. Liu, Y.; Yu, X. Carbon dioxide adsorption properties and adsorption/desorption kinetics of amine-functionalized KIT-6. Appl. Energy 2018, 211, 1080-1088. [CrossRef]

40. Niu, D.; Ma, Z.; Li, Y.; Shi, J. Synthesis of Core-Shell Structured Dual-Mesoporous Silica Spheres with Tunable Pore Size and Controllable Shell Thickness. J. Am. Chem. Soc. 2010, 132, 15144-15147. [CrossRef]

41. Hong, R.Y.; Chen, L.L.; Li, J.H.; Li, H.Z.; Zheng, Y.; Ding, J. Preparation and application of polystyrene-grafted ZnO nanoparticles. Polym. Adv. Technol. 2007, 18, 901-909. [CrossRef]

42. Chen, Y.; Gao, Y.; Da Silva, L.P.; Pirraco, R.P.; Ma, M.; Yang, L.; Reis, R.L.; Chen, J. A thermo-/pH-responsive hydrogel (PNIPAM-PDMA-PAA) with diverse nanostructures and gel behaviors as a general drug carrier for drug release. Polym. Chem. 2018, 9, 4063-4072. [CrossRef]

43. Watts, J.F.; Wolstenholme, J. An Introduction to Surface Analysis by XPS and AES; Wiley: Hoboken, NJ, USA, 2003; pp. 5-6.

44. Chen, M.; Wu, L.; Zhou, S.; You, B. A Method for the Fabrication of Monodisperse Hollow Silica Spheres. Adv. Mater. 2006, 18, 801-806. [CrossRef]

45. Whitfield, R.; Parkatzidis, K.; Rolland, M.; Truong, N.P.; Anastasaki, A. Tuning Dispersity by Photo-Induced ATRP: Monomodal Distributions with ppm Copper Concentration. Angew. Chem. Int. Ed. 2019, 58, 13323-13328. [CrossRef]

46. Whitfield, R.; Truong, N.P.; Messmer, D.; Parkatzidis, K.; Rolland, M.; Anastasaki, A.; Phuoc, N.T.; Parkatzidis, K. Tailoring polymer dispersity and shape of molecular weight distributions: Methods and applications. Chem. Sci. 2019, 10, 8724-8734. [CrossRef]

47. Zhu, Y.; Shi, J.; Shen, W.; Chen, H.; Dong, X.; Ruan, M. Preparation of novel hollow mesoporous silica spheres and their sustained-release property. Nanotechnology 2005, 16, 2633-2638. [CrossRef]

48. Wang, Y.; Bi, K.; Shu, J.; Liu, X.; Xu, J.; Deng, G. Ultrasound-controlled DOX-SiO2 nanocomposites enhance the antitumour efficacy and attenuate the toxicity of doxorubicin. Nanoscale 2019, 11, 4210-4218. [CrossRef]

49. Ardeshirzadeh, B.; Anaraki, N.A.; Irani, M.; Rad, L.R.; Shamshiri, S. Controlled release of doxorubicin from electrospun PEO/chitosan/graphene oxide nanocomposite nanofibrous scaffolds. Mater. Sci. Eng. C 2015, 48, 384-390. [CrossRef]

50. Chang, B.; Sha, X.; Guo, J.; Jiao, Y.; Wang, C.; Yang, W. Thermo and pH dual responsive, polymer shell coated, magnetic mesoporous silica nanoparticles for controlled drug release. J. Mater. Chem. 2011, 21, 9239-9247. [CrossRef] 
51. Bardajee, G.R.; Hooshyar, Z.; Farsi, M.; Mobini, A.; Sang, G. Synthesis of a novel thermo/pH sensitive nanogel based on salep modified graphene oxide for drug release. Mater. Sci. Eng. C 2017, 72, 558-565. [CrossRef]

52. He, Q.; Shi, J. Mesoporous silica nanoparticle based nano drug delivery systems: Synthesis, controlled drug release and delivery, pharmacokinetics and biocompatibility. J. Mater. Chem. 2011, 21, 5845-5855. [CrossRef]

53. Chastek, T.T.; Wadajkar, A.; Nguyen, K.T.; Hudson, S.D.; Chastek, T.Q. Polyglycol-templated synthesis of poly (N-isopropyl acrylamide) microgels with improved biocompatibility. Colloid Polym. Sci. 2010, $288,105$. [CrossRef]

(C) 2019 by the authors. Licensee MDPI, Basel, Switzerland. This article is an open access article distributed under the terms and conditions of the Creative Commons Attribution (CC BY) license (http://creativecommons.org/licenses/by/4.0/). 